\title{
The remarkable journey of adaptation of the Plasmodium falciparum malaria parasite to New World anopheline mosquitoes
}

\author{
Alvaro Molina-Cruz ${ }^{+}$, Carolina Barillas-Mury \\ Laboratory of Malaria and Vector Research, National Institute of Allergy and Infectious Diseases, \\ National Institutes of Health, Rockville, Maryland, USA
}

\begin{abstract}
Plasmodium falciparum originated in Africa, dispersed around the world as a result of human migration and had to adapt to several different indigenous anopheline mosquitoes. Anophelines from the New World are evolutionary distant form African ones and this probably resulted in a more stringent selection of Plasmodium as it adapted to these vectors. It is thought that Plasmodium has been genetically selected by some anopheline species through unknown mechanisms. The mosquito immune system can greatly limit infection and $\mathrm{P}$. falciparum evolved a strategy to evade these responses, at least in part mediated by $\mathrm{Pfs} 47$, a highly polymorphic gene. We propose that adaptation of $\mathrm{P}$. falciparum to new vectors may require evasion of their immune system. Parasites with a Pfs 47 haplotype compatible with the indigenous mosquito vector would be able to survive and be transmitted. The mosquito antiplasmodial response could be an important determinant of $\mathrm{P}$. falciparum population structure and could affect malaria transmission in the Americas.
\end{abstract}

Key words: malaria - Plasmodium falciparum - Anopheles - adaptation - mosquito - Americas

In spite of the great advances in disease control achieved in the past decade, malaria remains one of the most devastating infectious diseases to humankind. The disease, caused by Plasmodium protozoan parasites, is transmitted by anopheline mosquitoes. It threatens 1.2 billion people worldwide, with an estimated 219 million infections and 660,000 deaths in 2010 (WHO 2012). Although $90 \%$ of the mortality from malaria occurs in Africa, the American continent and the Caribbean have 119 million people at risk, with one million infections and 1,100 deaths estimated for 2010 (WHO 2012). In the Americas, $76.7 \%$ of infections are caused by Plasmodium vivax and $23.3 \%$ caused by Plasmodium falciparum. Brazil has the largest incidence of malaria, with $41 \%$ of the cases (WHO 2012).

In general, anopheline mosquitoes from the New World are less efficient vectors of malaria than African ones. This became dramatically evident during the transitory introduction of Anopheles arabiensis (member of the Anopheles gambiae species complex) to Brazil in the 1930 's, which caused a serious increase in the prevalence of malaria with mortality rates of $20-25 \%$ (Parmakelis et al. 2008). One of the factors that results in lower transmission of human malarias by New World anophelines is their feeding preference. For example, major malaria vectors from sub-Saharan Africa, such as An. gambiae and Anopheles funestus, have an anthropophilic index

doi: 10.1590/0074-0276130553

Financial support: Intramural Research Program/DIR/NIAID/NIH

+Corresponding author: amolina-cruz@niaid.nih.gov

Received 27 November 2013

Accepted 25 February 2014 (the probability of feeding on humans over other animals) of $80-100 \%$; while in the vectors from the Americas the index is usually less than 50\% (Bruce-Chwatt et al. 1966, Carter \& Mendis 2002, Hay et al. 2010, Sinka et al. 2010a, b). Nevertheless, other mosquito and parasite factors, including the mosquito immune system, may also be important determinants of the efficiency of malaria transmission.

In this review we discuss the origin and global dispersion of $P$. falciparum throughout the world and the evidence for adaptation of Plasmodium parasites to different mosquito vectors. The role of the mosquito immune system in determining susceptibility to Plasmodium infection and the evidence for a mechanism of $P$. falciparum evasion of mosquito immunity will be presented. This background information is used to explore the potential role of the mosquito immune system as a barrier to adaptation of P. falciparum to indigenous vectors of the Americas.

Out of Africa: P. falciparum geographic origin and dispersal - Several lines of evidence indicate that $P$. falciparum originated in sub-Saharan Africa. It has been recently found that great apes from Africa harbour high diversity of Plasmodium species closely related to $P$. falciparum and that west African gorillas (Gorilla gorilla) harbour infections with a parasite that is nearly genetically identical to $P$. falciparum, strongly suggesting that $P$. falciparum originated in African gorillas and transferred to humans relatively recently (Liu et al. 2010, Prugnolle et al. 2011). Previous molecular genetic analysis of P. falciparum isolates from around the world has consistently shown higher genetic diversity in African isolates (Hartl 2004). Furthermore, the genetic diversity of $P$. falciparum populations decreases as a function of geographic distance from sub-Saharan Africa, also consistent with an African origin (Tanabe et al. 2010, 2013). 
As malaria-infected humans migrated out of Africa, they carried P. falciparum with them, leaving their African mosquito vectors behind. This initiated a remarkable journey that led to the adaptation of the parasite to more than 34 different anopheline mosquito species worldwide (Sinka et al. 2012). Phylogenetic analysis of $P$. falciparum isolates indicates that the parasite population from the Americas has lower genetic diversity than those from the Old World (Anderson et al. 2000, Conway et al. 2000, Conway 2003, Joy et al. 2003, Neafsey et al. 2008, Yalcindag et al. 2012). Microsatellites, nuclear genes and mitochondrial DNA analysis indicate that American isolates are genetically closer to African haplotypes than to Asian ones, consistent with an introduction of African parasites into the American continent (Anderson et al. 2000, Joy et al. 2003, Yalcindag et al. 2012). Most historical, archaeological and genetic evidence suggest that malaria was introduced during or after the European conquest of the Americas (de Castro \& Singer 2005, Webb Jr 2009, Yalcindag et al. 2012).

The $P$. falciparum populations that arrived to the Americas during the last 500 years probably had considerable genetic diversity. Historical evidence shows that more than seven million African slaves were brought to the New World between 1514-1866 (Voyages-Database, available from slavevoyages.org/tast/index.faces) (Figure). Today, the region in West Africa where most of these slaves originated presents a high prevalence of $P$. falciparum malaria, as well as large genetic diversity of the parasite (WHO 2012, Yalcindag et al. 2012). It is therefore very likely that a high percentage of African slaves carried P. falciparum infections and that the parasites they carried had a genetic diversity probably higher than what is found today in the Americas. The apparent decrease in genetic diversity could be the result of a random founder effect or genetic drift, due to the lower transmission in the New World. Alternatively, it may have been the result of adaptation by genetic selection or most likely, by a combination of these two factors.

There is historical evidence for significant malaria transmission that resulted in major outbreaks in Jamaica (1655-1656), Hispaniola (1794-1795, 1802) and Illinois (1850) (Webb Jr 2009). This suggests that a drastic founder effect due to low malaria transmission in the Americas probably did not take place. Adaptation through a genetic selection process could also have reduced the genetic diversity of $P$. falciparum in the Americas. Particular $P$. falciparum genotypes could have been selected by either or both of its obligatory hosts: humans and mosquitoes. In the case of humans, the large number of African slaves should have maintained high genetic diversity of $P$. falciparum in areas with significant transmission and there is no evidence of differential susceptibility to malaria in other ethnic groups that could have driven selection. More recently, however, the widespread use of the antimalarial drug chloroquine may have greatly reduced the genetic diversity of P. falciparum (Wootton et al. 2002).

Let us consider now the other host, the anopheline malaria vectors in the New World. Adaptation to local mosquitoes was undoubtedly an initial requirement for $P$. falciparum to be transmitted in the New World. According to the present geographic distribution of anophelines and the slave trade disembarking ports (Figure), some of the first indigenous vectors that $P$. falciparum encountered were Anopheles albimanus, Anopheles aquasalis, Anopheles darlingi, Anopheles albitarsis and Anopheles quadrimaculatus. Old and New World anophelines are evolutionary distant since they diverged some 95 million years ago, when the South American continent separated from what is now Africa (Moreno et al. 2010). It is, there-

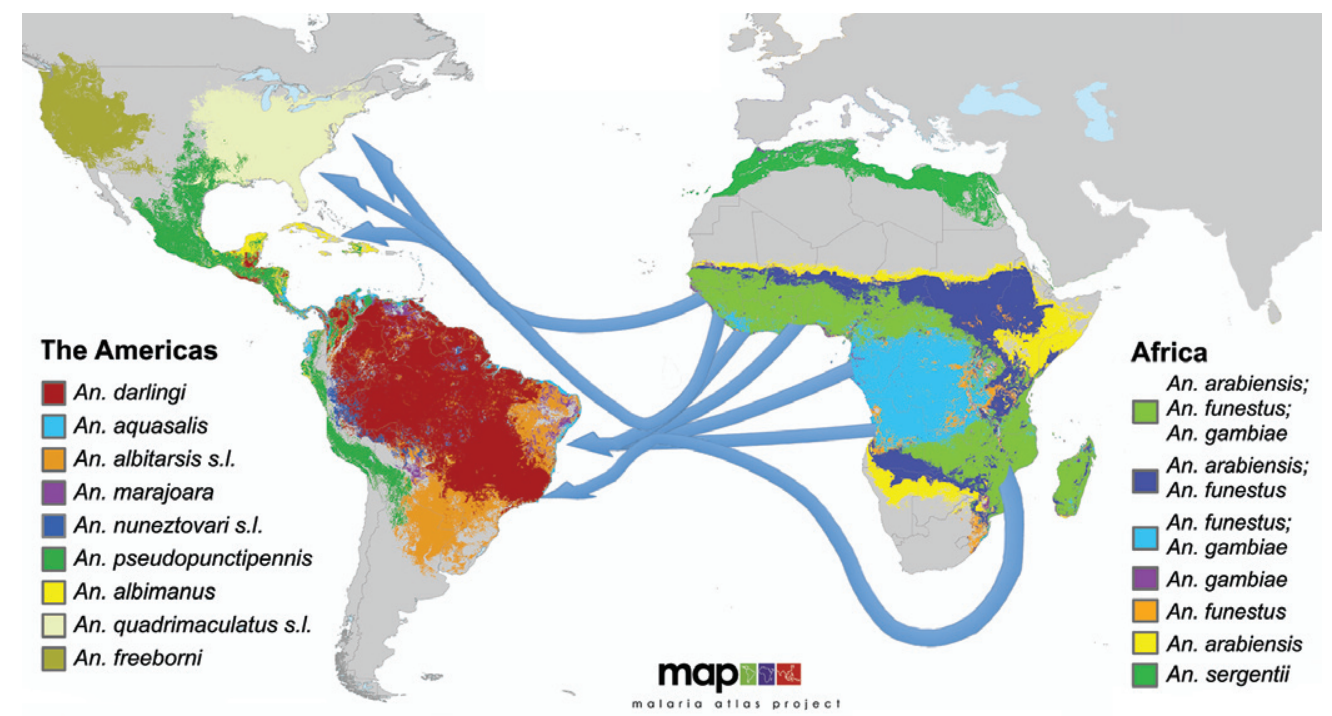

Map of the major mosquito vectors of malaria in Africa and the Americas and slave-trade routes to the New World. Plasmodium falciparum is thought to have arrived to the Americas in malaria-infected Africans brought during the transatlantic slave trade between 1514-1866. The blue arrows indicate general transatlantic slave trade routes. The malaria vector map is from the Malaria Atlas Project (Sinka et al. 2012) and was modified to illustrate the slave trade routes. 
fore, not surprising that there are marked genetic, ecological and behavioural differences between New World and African anopheline vectors (Sinka et al. 2010a, b). This probably resulted in a more stringent selection of Plasmodium as it adapted to these vectors.

Evidence for adaptation of Plasmodium to different anophelines by genetic selection - There are several lines of evidence for adaptation of Plasmodium to new vectors through genetic selection by different anopheline species. One case involves $P$. vivax transmission in different areas of Southern Mexico (Joy et al. 2008). In this region, the low altitude $(<100 \mathrm{~m})$ mosquito An. albimanus transmits malaria in coastal areas, whereas in the foothills malaria is transmitted mainly by the higher altitude mosquito Anopheles pseudopunctipennis (Rodriguez et al. 2000). Interestingly, genetically distinct populations of $P$. vivax have been identified in these two geographic areas. Furthermore, laboratory infections showed that An. albimanus is more susceptible to infection by coastal P. vivax genotypes, whereas An. pseudopunctipennis is more susceptible to foothill parasite genotypes (Joy et al. 2008). This suggests that selection of $P$. vivax by local anophelines has led to adaptation of the parasite to different vectors.

In the case of $P$. falciparum, it has been found that a laboratory line of putative African origin (NF-54) and a clone from this line (3D7), infect poorly or not at all the New World An. albimanus, the main malaria vector in Central American and the Caribbean (Grieco et al. 2005, Garver 2006, Baton \& Ranford-Cartwright 2012). Conversely, the African An. gambiae tends to be infected more efficiently with African P. falciparum isolates than with isolates from Thailand (Hume et al. 2007), consistent with genetic selection of different $P$. falciparum strains by anopheline vectors present in different continents. Taken together, these studies suggest that genetic selection of Plasmodium during its adaptation to different anopheline vectors does occur in nature. However, the mechanism of the adaptation has not been identified.

The anopheline immune system as a barrier to Plasmodium adaptation - An. gambiae mosquitoes can mount robust and effective antiplasmodial immune responses capable of greatly reducing or eliminating Plasmodium infection (Osta et al. 2004). The thioester containing protein-1 (TEP1), a key component of the An. gambiae complement-like system, is one of most potent antiplasmodial mosquito immune responses (Blandin et al. 2004, Fraiture et al. 2009, Povelones et al. 2009). TEP1 binds to the surface of Plasmodium ookinetes (the stage that invades the mosquito midgut epithelia) and triggers the formation of a complex that causes lysis and/or melanotic encapsulation of the invading parasite. Recent studies indicate that exposure of the parasite to nitration reactions during their transit through the invaded midgut epithelial cell is a prerequisite of TEP1 binding (Oliveira et al. 2012). Although the An. gambiae complement-like system has been shown to be very effective at eliminating some parasite species, such as Plasmodium berghei and Plasmodium yoelii (mouse malaria parasites) (Blandin et al. 2004, Jaramillo-Gutierrez et al. 2009), it is less active or not active against sympatric $P$. falciparum from Africa (Cohuet et al. 2006, Nsango et al. 2012). Furthermore, it was recently found that some African P. falciparum isolates are able to evade the complement-like system of an An. gambiae refractory strain that was selected to be refractory to Plasmodium cynomolgi and mounts a very strong antiplasmodial response. In contrast, isolates from non-African regions are efficiently killed and encapsulated by this refractory strain (Molina-Cruz et al. 2012). This suggests that sympatric P. falciparum strains are adapted to evade the An. gambiae immune system.

Using linkage mapping and functional genetics, $P f_{s} 47$ was identified as a gene that allows some African strains of $P$. falciparum to evade the An. gambiae immune system (Molina-Cruz et al. 2013). Pfs47 is a member of the 6-cys protein family and is expressed on the surface of female gametocytes and ookinetes (van Schaijk et al. 2006, Molina-Cruz et al. 2013). The $P f_{s} 47$ homologue in $P$. berghei is required for female gamete fertility (van Schaijk et al. 2006), but $P f_{s} 47$ is not essential for $P$. falciparum fertilisation. Although the mechanism of action of $P f_{s} 47$ is not yet known, $P f_{s} 47$ appears to be actively inhibiting protein nitration in the mosquito midgut cell (Molina-Cruz et al. 2013), which is a prerequisite for TEP1-mediated parasite elimination (Oliveira et al. 2012). Pfs 47 inhibits the induction of two enzymes, NOX5 and HPX2, that mediate nitration in response to Plasmodium invasion (Molina-Cruz et al. 2013). Because the Jun N-terminal kinase (JNK) pathway mediates the induction of these two enzymes (Garver et al. 2013), $P f s 47$ seems to disrupt JNK signalling by interacting with a critical mosquito target protein that remains to be identified.

The fact that Plasmodium evolved a mechanism to evade the mosquito complement-like system indicates that this defense mechanism is an important determinant of malaria transmission. Evidence that the mosquito immune system may be a barrier for adaptation of Plasmodium to a new vector comes from studies in Anopheles quadriannulatus, a non-malaria vector from Africa. In this anopheline, disruption of the mosquito complementlike system by silencing of TEP1 expression greatly increased susceptibility to $P$. falciparum infection (Habtewold et al. 2008).

The $P f_{S} 47$ gene is likely to be involved in adaptation to new vectors, due to its role in evasion of the mosquito immune system. Population genetic analysis has shown that $P f_{S} 47$ is a highly polymorphic protein with different haplotypes predominating in different continents, indicating strong geographic genetic structure (Anthony et al. 2007, Manske et al. 2012). In fact, analysis of whole genome sequences of 227 P. falciparum isolates from Africa, Asia and Papua New Guinea revealed that $P f_{s} 47$ has one of the highest levels of geographic genetic structure when compared to polymorphisms in the rest of the genome (Manske et al. 2012). Pfs 47 was found to have higher genetic diversity in African P. falciparum isolates compared to other continents (Anthony et al. 2007, Manske et al. 2012) and one of the polymorphisms in $P f_{s} 47$ has a fixed difference between Africa and other continents (Manske et al. 2012). We propose that the 
geographic genetic structure of $P f_{s} 47$ may be largely determined by selection imposed by the immune system of anopheline mosquitoes from different regions of the world and that interaction of $P f_{s} 47$ haplotypes with particular haplotypes of its target in the mosquito has been critical for adaptation of the parasite to new vectors.

Based on this working hypothesis, one can draw several important predictions: (i) different anopheline vector species could harbour different haplotypes of the protein that interacts with $P f_{s} 47$ and malaria transmission would be enhanced when compatible parasite-vector combinations interact. As a result, the mosquito species present in a given geographic area selects for compatible $P f s 47$ haplotypes; (ii) the population genetic structure observed for $P f_{S} 47$ (and for the parasite in general) may be better understood by correlating $P f_{s} 47$ haplotypes to mosquito vector species present in a given geographic region. This correlation should be even stronger with the haplotypes of the mosquito target of $P f s 47$, a gene that has not been identified; (iii) $P f s 47$ may be a good target for a transmission blocking strategy in An. gambiae. Binding of antibodies from a vaccine against $P f s 47$ or inactivation with a drug, could prevent the interaction of $P f_{S} 47$ with the mosquito target protein and disrupt the ability of the parasite to evade the mosquito immune system.

Experimental models of malaria transmission in Brazil - A wealth of information on mosquito-parasite interactions has been generated in the last 10 years, mostly in An. gambiae and Anopheles stephensi, the major malaria vectors in Africa and India, respectively. These two mosquito species can be readily colonised and are susceptible to infection with several parasite species, such as murine malarias (P. berghei and P. yoelii) (Blandin et al. 2004, Jaramillo-Gutierrez et al. 2009) or human malaria gametocyte cultures ( $P$. falciparum) (Luckhart et al. 1998, Dong et al. 2006, Garver et al. 2009); making them robust laboratory models to study the biology of malaria transmission. Although malaria is an endemic disease in the Americas, especially in the Amazon Region, relatively little is known about the biology of parasite transmission by mosquito vectors in Brazil, such as An. darling or An. aquasalis. Research in this area would be greatly facilitated by establishing robust experimental systems. Until recently, An. darlingi, the major vector in Brazil, had not been colonised because this species does not mate readily in captivity. As a result, all experimental work has been done using field-collected larvae that are reared in the laboratory until they reach the adult stage. However, the recent report of adaptation of $A n$. darlingi to laboratory conditions could be a major breakthrough in the field (Villareal et al. 2013).

In general, anophelines are highly adapted to a particular ecological niche and the immune systems of African and New World mosquitoes probably have evolved to deal with the microorganisms in their natural habitat. A broad genome-wide comparison of the immune effector genes between anopheline mosquitoes will soon be possible with the completion of the sequence of several genomes. This analysis may reveal important differences in organisation and/or expansions of specific immune effector genes in particular anopheline species. Given the great evolutionary distance between New World vectors and An. gambiae, it is likely that there are some important differences in their antiplasmodial responses. Recent studies on the immune response of An. aquasalis to $P$. vivax infection revealed that the participation of the signal transducer and activator of transcription pathway in antiplasmodial immunity, first described in An. gambiae, is also taking place in this system (Bahia et al. 2010). However, reducing detoxification of reactive oxygen species by silencing catalase enhanced $P$. vivax infection in An. aquasalis (Bahia et al. 2013), but had the opposite effect when An. gambiae mosquitoes are infected with the murine malaria parasite $P$. berghei (Molina-Cruz et al. 2008). These results highlighting the importance of comparative studies to validate models built based on different mosquito-parasite combinations, as some responses may not be universal.

Our working hypothesis also indicates that it is critical to consider the compatibility between the mosquito-parasite combinations being used when establishing experimental models of malaria transmission, as mosquitoes could mount strong immune responses to one parasite strain, but not respond at all when infected with a different strain. P. falciparum NF-54 is a laboratory strain of African origin that is commonly used in trials to assess the efficiency of transmission blocking drugs or vaccines. However, parasites with the NF-54 haplotype of $P f_{S} 47$ are rarely found in human isolates outside of Africa and infect An. albimanus very poorly; suggesting that parasites with this haplotype may not infect vectors outside of Africa very efficiently. The adaptation of Plasmodium isolates from the same geographic area as the mosquito vectors to in vitro culture may be the best way to ensure a compatible combination.

In conclusion, as humans migrated, they dispersed $P$. falciparum around the world and the parasite had to adapt to different indigenous anopheline mosquitoes. In the case of the Americas, $P$. falciparum encountered anophelines that are evolutionary distant from African vectors. Mosquitoes can mount effective immune responses that represent an important barrier to malaria transmission. In response, $P$. falciparum has evolved the capacity to evade the An. gambiae immune system through a mechanism that involves $P f_{S} 47$. We propose that those parasites with $P f_{s} 47$ alleles that were compatible with the anopheline species present in a new geographic region could be transmitted because they were able to evade the mosquito immune system and that genetic selection by interaction with the vectors immune systems shaped the population of $P$. falciparum parasites present in the New World.

\section{ACKNOWLEDGEMENTS}

To the anonymous reviewers, for their insightful comments and suggestions, and to Marcia B Brown and Mark A Johnson, for editorial assistance.

\section{REFERENCES}

Anderson TJ, Haubold B, Williams JT, Estrada-Franco JG, Richardson L, Mollinedo R, Bockarie M, Mokili J, Mharakurwa S, French N, Whitworth J, Velez ID, Brockman AH, Nosten F, Fer- 
reira MU, Day KP 2000. Microsatellite markers reveal a spectrum of population structures in the malaria parasite Plasmodium falciparum. Mol Biol Evol 17: 1467-1482.

Anthony TG, Polley SD, Vogler AP, Conway DJ 2007. Evidence of non-neutral polymorphism in Plasmodium falciparum gamete surface protein genes $P f_{s} 47$ and $P f_{s} 48 / 45$. Mol Biochem Parasitol 156: $117-123$.

Bahia AC, Kubota MS, Tempone AJ, Pinheiro WD, Tadei WP, Secundino NF, Traub-Cseko YM, Pimenta PF 2010. Anopheles aquasalis infected by Plasmodium vivax displays unique gene expression profiles when compared to other malaria vectors and plasmodia. PLoS ONE 5: e9795.

Bahia AC, Oliveira JH, Kubota MS, Araujo HR, Lima JB, Rios-Velasquez CM, Lacerda MV, Oliveira PL, Traub-Cseko YM, Pimenta PF 2013. The role of reactive oxygen species in Anopheles aquasalis response to Plasmodium vivax infection. PLoS ONE 8: e57014.

Baton LA, Ranford-Cartwright LC 2012. Ookinete destruction within the mosquito midgut lumen explains Anopheles albimanus refractoriness to Plasmodium falciparum (3D7A) oocyst infection. Int J Parasitol 42: 249-258.

Blandin S, Shiao SH, Moita LF, Janse CJ, Waters AP, Kafatos FC, Levashina EA 2004. Complement-like protein TEP1 is a determinant of vectorial capacity in the malaria vector Anopheles gambiae. Cell 116: 661-670.

Bruce-Chwatt LJ, Garrett-Jones C, Weitz B 1966. Ten years' study (1955-64) of host selection by anopheline mosquitos. Bull World Health Organ 35: 405-439.

Carter R, Mendis KN 2002. Evolutionary and historical aspects of the burden of malaria. Clin Microbiol Rev 15: 564-594.

Cohuet A, Osta MA, Morlais I, Awono-Ambene PH, Michel K, Simard F, Christophides GK, Fontenille D, Kafatos FC 2006. Anopheles and Plasmodium: from laboratory models to natural systems in the field. EMBO Rep 7: 1285-1289.

Conway DJ 2003. Tracing the dawn of Plasmodium falciparum with mitochondrial genome sequences. Trends Genet 19: 671-674.

Conway DJ, Fanello C, Lloyd JM, Al-Joubori BM, Baloch AH, Somanath SD, Roper C, Oduola AM, Mulder B, Povoa MM, Singh B, Thomas AW 2000. Origin of Plasmodium falciparum malaria is traced by mitochondrial DNA. Mol Biochem Parasitol 111: $163-171$.

de Castro MC, Singer BH 2005. Was malaria present in the Amazon before the European conquest? Available evidence and future research agenda. $J$ Archaeol Sci 32: 337-340.

Dong Y, Aguilar R, Xi Z, Warr E, Mongin E, Dimopoulos G 2006. Anopheles gambiae immune responses to human and rodent Plasmodium parasite species. PLoS Pathog 2: e52.

Fraiture M, Baxter RH, Steinert S, Chelliah Y, Frolet C, QuispeTintaya W, Hoffmann JA, Blandin SA, Levashina EA 2009. Two mosquito LRR proteins function as complement control factors in the TEP1-mediated killing of Plasmodium. Cell Host Microbe 5: $273-284$

Garver LS 2006. The peptidoglycan recognition protein PGRP-SCla is essential for toll signaling and phagocytosis of Staphylocloccus aureus in Drosophila. Proc Natl Acad Sci USA 103: 660-665.

Garver LS, Dong Y, Dimopoulos G 2009. Caspar controls resistance to Plasmodium falciparum in diverse anopheline species. PLoS Pathog 5: e1000335.

Garver LS, Oliveira GA, Barillas-Mury C 2013. The JNK pathway is a key mediator of Anopheles gambiae antiplasmodial immunity. PLoS Pathog 9: e1003622.
Grieco JP, Achee NL, Roberts DR, Andre RG 2005. Comparative susceptibility of three species of Anopheles from Belize, Central America, to Plasmodium falciparum (NF-54). J Am Mosq Control Assoc 21: 279-290.

Habtewold T, Povelones M, Blagborough AM, Christophides GK 2008. Transmission blocking immunity in the malaria non-vector mosquito Anopheles quadriannulatus species A. PLoS Pathog 4: e1000070.

Hartl DL 2004. The origin of malaria: mixed messages from genetic diversity. Nat Rev Microbiol 2: 15-22.

Hay SI, Sinka ME, Okara RM, Kabaria CW, Mbithi PM, Tago CC, Benz D, Gething PW, Howes RE, Patil AP, Temperley WH, Bangs MJ, Chareonviriyaphap T, Elyazar IR, Harbach RE, Hemingway J, Manguin S, Mbogo CM, Rubio-Palis Y, Godfray HC 2010. Developing global maps of the dominant Anopheles vectors of human malaria. PLoS Med 7: e1000209.

Hume JC, Tunnicliff M, Ranford-Cartwright LC, Day KP 2007. Susceptibility of Anopheles gambiae and Anopheles stephensi to tropical isolates of Plasmodium falciparum. Malar J 6: 139.

Jaramillo-Gutierrez G, Rodrigues J, Ndikuyeze G, Povelones M, Molina-Cruz A, Barillas-Mury C 2009. Mosquito immune responses and compatibility between Plasmodium parasites and anopheline mosquitoes. BMC Microbiol 9: 154.

Joy DA, Feng X, Mu J, Furuya T, Chotivanich K, Krettli AU, Ho M, Wang A, White NJ, Suh E, Beerli P, Su XZ 2003. Early origin and recent expansion of Plasmodium falciparum. Science 300: 318-321.

Joy DA, Gonzalez-Ceron L, Carlton JM, Gueye A, Fay M, McCutchan TF, Su X-z 2008. Local adaptation and vector-mediated population structure in Plasmodium vivax malaria. Mol Biol Evol 25: $1245-1252$

Liu W, Li Y, Learn GH, Rudicell RS, Robertson JD, Keele BF, Ndjango JB, Sanz CM, Morgan DB, Locatelli S, Gonder MK, Kranzusch PJ, Walsh PD, Delaporte E, Mpoudi-Ngole E, Georgiev AV, Muller MN, Shaw GM, Peeters M, Sharp PM, Rayner JC, Hahn BH 2010. Origin of the human malaria parasite Plasmodium falciparum in gorillas. Nature 467: 420-425.

Luckhart S, Vodovotz Y, Cui L, Rosenberg R 1998. The mosquito Anopheles stephensi limits malaria parasite development with inducible synthesis of nitric oxide. Proc Natl Acad Sci USA 95: 5700-5705.

Manske M, Miotto O, Campino S, Auburn S, Almagro-Garcia J, Maslen G, O’Brien J, Djimde A, Doumbo O, Zongo I, Ouedraogo JB, Michon P, Mueller I, Siba P, Nzila A, Borrmann S, Kiara SM, Marsh K, Jiang H, Su XZ, Amaratunga C, Fairhurst R, Socheat D, Nosten F, Imwong M, White NJ, Sanders M, Anastasi E, Alcock D, Drury E, Oyola S, Quail MA, Turner DJ, Ruano-Rubio V, Jyothi D, Amenga-Etego L, Hubbart C, Jeffreys A, Rowlands K, Sutherland C, Roper C, Mangano V, Modiano D, Tan JC, Ferdig MT, Amambua-Ngwa A, Conway DJ, Takala-Harrison S, Plowe CV, Rayner JC, Rockett KA, Clark TG, Newbold CI, Berriman M, MacInnis B, Kwiatkowski DP 2012. Analysis of Plasmodium falciparum diversity in natural infections by deep sequencing. Nature 487: 375-379.

Molina-Cruz A, DeJong RJ, Charles B, Gupta L, Kumar S, JaramilloGutierrez G, Barillas-Mury C 2008. Reactive oxygen species modulate Anopheles gambiae immunity against bacteria and Plasmodium. J Biol Chem 283: 3217-3223.

Molina-Cruz A, DeJong RJ, Ortega C, Haile A, Abban E, Rodrigues J, Jaramillo-Gutierrez G, Barillas-Mury C 2012. Some strains of Plasmodium falciparum, a human malaria parasite, evade the complement-like system of Anopheles gambiae mosquitoes. Proc Natl Acad Sci USA 109: e1957-e1962. 
Molina-Cruz A, Garver LS, Alabaster A, Bangiolo L, Haile A, Winikor J, Ortega C, van Schaijk BCL, Sauerwein RW, Taylor-Salmon E, Barillas-Mury C 2013. The human malaria parasite Pfs 47 gene mediates evasion of the mosquito immune system. Science 340: 984-987.

Moreno M, Marinotti O, Krzywinski J, Tadei WP, James AA, Achee NL, Conn JE 2010. Complete mtDNA genomes of Anopheles darlingi and an approach to anopheline divergence time. Malar J 9: 127.

Neafsey DE, Schaffner SF, Volkman SK, Park D, Montgomery P, Milner Jr DA, Lukens A, Rosen D, Daniels R, Houde N, Cortese JF, Tyndall E, Gates C, Stange-Thomann N, Sarr O, Ndiaye D, Ndir O, Mboup S, Ferreira MU, Moraes SL, Dash AP, Chitnis CE, Wiegand RC, Hartl DL, Birren BW, Lander ES, Sabeti PC, Wirth DF 2008. Genome-wide SNP genotyping highlights the role of natural selection in Plasmodium falciparum population divergence. Genome Biol 9: R171.

Nsango SE, Abate L, Thoma M, Pompon J, Fraiture M, Rademacher A, Berry A, Awono-Ambene PH, Levashina EA, Morlais I 2012. Genetic clonality of Plasmodium falciparum affects the outcome of infection in Anopheles gambiae. Int J Parasitol 42: 589-595.

Oliveira GA, Lieberman J, Barillas-Mury C 2012. Epithelial nitration by a peroxidase/NOX5 system mediates mosquito antiplasmodial immunity. Science 335: 856-859.

Osta MA, Christophides GK, Vlachou D, Kafatos FC 2004. Innate immunity in the malaria vector Anopheles gambiae: comparative and functional genomics. J Exp Biol 207: 2551-2563.

Parmakelis A, Russello MA, Caccone A, Marcondes CB, Costa J, Forattini OP, Sallum MA, Wilkerson RC, Powell JR 2008. Historical analysis of a near disaster: Anopheles gambiae in Brazil. Am J Trop Med Hyg 78: 176-178.

Povelones M, Waterhouse RM, Kafatos FC, Christophides GK 2009. Leucine-rich repeat protein complex activates mosquito complement in defense against Plasmodium parasites. Science 324: $258-261$.

Prugnolle F, Durand P, Ollomo B, Duval L, Ariey F, Arnathau C, Gonzalez JP, Leroy E, Renaud F 2011. A fresh look at the origin of Plasmodium falciparum, the most malignant malaria agent. PLoS Pathog 7: e1001283.

Rodriguez MH, Gonzalez-Ceron L, Hernandez JE, Nettel JA, Villarreal C, Kain KC, Wirtz RA 2000. Different prevalence of Plasmodium vivax phenotypes VK210 and VK247 associated with the distribution of Anopheles albimanus and Anopheles pseudopunctipennis in Mexico. Am J Trop Med Hyg 62: 122-127.

Sinka ME, Bangs M, Manguin S, Coetzee M, Mbogo C, Hemingway J, Patil A, Temperley W, Gething P, Kabaria C, Okara R, Van Boeckel T, Godfray HC, Harbach R, Hay S 2010a. The dominant Anopheles vectors of human malaria in Africa, Europe and the Middle East: occurrence data, distribution maps and bionomic précis. Parasit Vectors 3: 117.
Sinka ME, Bangs MJ, Manguin S, Rubio-Palis Y, Chareonviriyaphap T, Coetzee M, Mbogo CM, Hemingway J, Patil AP, Temperley WH, Gething PW, Kabaria CW, Burkot TR, Harbach RE, Hay SI 2012. A global map of dominant malaria vectors. Parasit Vectors 5: 69.

Sinka ME, Rubio-Palis Y, Manguin S, Patil AP, Temperley WH, Gething PW, Van Boeckel T, Kabaria CW, Harbach RE, Hay SI 2010b. The dominant Anopheles vectors of human malaria in the Americas: occurrence data, distribution maps and bionomic précis. Parasit Vectors 3: 72.

Tanabe K, Jombart T, Horibe S, Palacpac NM, Honma H, Tachibana SI, Nakamura M, Horii T, Kishino H, Mita T 2013. Plasmodium falciparum mitochondrial genetic diversity exhibits isolation-bydistance patterns supporting a sub-Saharan African origin. Mitochondrion 13: 630-636.

Tanabe K, Mita T, Jombart T, Eriksson A, Horibe S, Palacpac N, Ranford-Cartwright L, Sawai H, Sakihama N, Ohmae H, Nakamura M, Ferreira MU, Escalante AA, Prugnolle F, Bjorkman A, Farnert A, Kaneko A, Horii T, Manica A, Kishino H, Balloux F 2010. Plasmodium falciparum accompanied the human expansion out of Africa. Curr Biol 20: 1283-1289.

van Schaijk BC, van Dijk MR, van de Vegte-Bolmer M, van Gemert GJ, van Dooren MW, Eksi S, Roeffen WF, Janse CJ, Waters AP, Sauerwein RW 2006. Pfs 47, paralog of the male fertility factor $P f_{s} 48 / 45$, is a female specific surface protein in Plasmodium falciparum. Mol Biochem Parasitol 149: 216-222.

Villareal C, Vasquez GM, Escobedo-Vargas K, Huayanay-Repetto A, Lopez-Sifuentes V, Flores-Mendoza C, Lescano AG, Stell FM 2013. Establishment of an Anopheles darlingi colony under insectary conditions through natural copulation in Iquitos, Peru. Proceedings of the 62nd Annual Meeting, American Society of Tropical Medicine and Hygiene, ASTMH, Washington, p. 345.

Webb Jr JLA 2009. Humanity's burden: a global history of malaria, Cambridge University Press, New York, 236 pp.

WHO - World Health Organization 2012. World Malaria Report 2012. Available from: who.int/malaria/publications/world_malaria report_2012/en/.

Wootton JC, Feng X, Ferdig MT, Cooper RA, Mu J, Baruch DI, Magill AJ, Su XZ 2002. Genetic diversity and chloroquine selective sweeps in Plasmodium falciparum. Nature 418: 320-323.

Yalcindag E, Elguero E, Arnathau C, Durand P, Akiana J, Anderson TJ, Aubouy A, Balloux F, Besnard P, Bogreau H, Carnevale P, D'Alessandro U, Fontenille D, Gamboa D, Jombart T, Le Mire J, Leroy E, Maestre A, Mayxay M, Menard D, Musset L, Newton PN, Nkoghe D, Noya O, Ollomo B, Rogier C, Veron V, Wide A, Zakeri S, Carme B, Legrand E, Chevillon C, Ayala FJ, Renaud F, Prugnolle F 2012. Multiple independent introductions of Plasmodium falciparum in South America. Proc Natl Acad Sci USA 109: 511-516. 